\title{
Learning career management skills in Europe: a critical review
}

\author{
Ronald G. Sultana* \\ Euro-Mediterranean Centre for Educational Research, University of Malta, Msida \\ MSD, Malta
}

(Received 28 October 2009; final version received 10 December 2010)

\begin{abstract}
Career management skills (CMS) are increasingly touted as necessary for all citizens, young and adult, particularly given the realities of employment and self-employment in a knowledge-based society, where 'protean', 'portfolio' careers are expected to increasingly become the norm, and lifelong career guidance an entitlement of all citizens. This paper provides an account of how CMS are featuring ever more prominently on the agenda of many European countries, and explores how such skills are being defined, how and where they are being taught and assessed, and the various modalities by means of which they are integrated in education and training programmes in both the education and labour market sectors. Particular care is given to debates and tensions around the notion of CMS, and to considering trends and initiatives not only from a country-specific perspective, but also from a European one, given the interest of the European Commission in supporting policy development in the area through its Lifelong Learning Programme. The paper concludes by highlighting some of the more pressing issues that need to be addressed.
\end{abstract}

Keywords: career management skills; career guidance; European Lifelong Guidance Policy Network; lifelong career guidance

\section{Introduction and background}

This paper draws on some of the research and reflection that is taking place within the context of the European Lifelong Guidance Policy Network (ELGPN), a European commission-funded network made up of policy-maker representatives from the 27 European Union (EU) member states and two European Economic Area countries (Iceland and Norway). Network participants belong to the education and the labour market sectors, with a few representing the social partners and guidance associations. A small group of resource persons - of which the present author is one - provide expertise and resources to the network, helping to bridge policy, research and practice issues.

\footnotetext{
*Email: ronald.sultana@um.edu.mt 
The ELGPN, set up in 2007 and benefiting from European Commission support under its Lifelong Learning Programme, aims to stimulate European cooperation on lifelong guidance. While there is a long history of policy interest in career guidance in the EU (Watts, Sultana, and McCarthy 2010), the network is best seen as one of the outcomes triggered by the spate of reviews that started with the 2000 OECD study (2004), which was followed by those commissioned by a range of EU entities and agencies, including the ETF European Training Foundation (Sultana 2003, 2007a, 2007b), CEDEFOP the European Centre for the Development of Vocational Training (Sultana 2004, 2008), and DG Employment, Social Affairs and Equal Opportunities (Sultana and Watts 2006a, 2006b). These reviews, together with others carried out in middle- and low-income countries by the World Bank (Watts and Fretwell 2004), in the Middle East and North Africa (Sultana and Watts 2007, 2008), and in the West Balkans (Sweet 2006; Zelloth 2009) by ETF, used much the same methodology, ${ }^{1}$ and together constitute the most extensive and comparable database that has been generated internationally on career guidance policy and practice, involving over 50 countries in all (Watts and Sultana 2004; Watts 2008).

The ELGPN - and its precursor, the more informally constituted Lifelong Guidance Expert Group (2002-2007) - have been instrumental in ensuring that key concerns that emerged from the various reviews were adopted as a focus for policy attention by the European Council of Ministers of Education, first in 2004, and then again in 2008 (Council of the European Union 2004, 2008). In both instances, EU Council Resolutions - which give political direction to the EU - were endorsed with a view to better integrating lifelong guidance into lifelong learning strategies. In the most recent resolution, EU member states were invited to give special attention to four key areas, namely:

(1) the lifelong acquisition of career management skills (CMS);

(2) the facilitation of access by all citizens to guidance services;

(3) the ensuring of quality in guidance provision; and

(4) the encouragement of coordination and cooperation among the various national, regional and local stakeholders.

While the four goals are clearly interrelated, the ELGPN has established thematic working groups in order to reflect on the implications that each of these aspirations have for policy in the career guidance field. This paper considers the first of these four goals, and draws on material generated over a twoyear period (2008-2009) within the context of one of the working groups in order to reflect on the meaning of CMS in a European context, and how these skills are being promoted, particularly through the delivery of career guidance services in the education and labour market sectors in different countries. This material included responses to two surveys from representatives of $15 \mathrm{EU}$ member states participating in the CMS thematic working group - namely 
Austria, the Czech Republic, Denmark, Estonia, Finland, France, Italy, Lithuania, Malta, the Netherlands, Portugal, Slovakia, Slovenia, Sweden and the UK (Scotland), who provided qualitative input in relation to a range of open-ended questions. The first survey focused on the definition of CMS, the rationale underpinning their implementation, how, when and by whom they are taught within education, training and Public Employment Service (PES) contexts, and how they are assessed, if at all. The second survey considered much the same themes, but looked more closely at the way CMS are fostered in education and labour market settings in relation to the specific needs of special target groups, such as persons with special needs, immigrants, ethnic minorities and travelling people.

In the case of both surveys, responses were made by the ELGPN country delegates, after due consultation with the relevant authorities. The latter generally included service managers located in the education and labour ministries, but occasionally also those in family and social policy ministries which are sometimes responsible for providing CG services. As such, the information provided through these surveys represents the official position and perspective of the policy-makers in the 15 participating countries, with additional insights emerging during the discussions of the thematic working group, as well as through input from other ELGPN members during plenary meetings of the network. The survey responses were analysed through the identification of key categories and properties of categories embedded in the texts, and organised in such a way as to facilitate the recognition of patterns and trends. Initial analyses were shared with members of the thematic working group in order to ensure correct understanding of the material submitted, and to allow competing interpretations to emerge. In the case of both surveys, therefore, the main objective was to generate insights into what is perforce a complex and diverse situation both across EU member states, and within them. The survey questions therefore served rather more as an inroad into understanding practices, with the key intent being the articulation of a platform for critical discussion and further qualitative probing, rather than the development of robust quantitative measures.

In responding to both surveys, EU member states also provided examples of interesting practice, as well as a range of documents and resources that are currently in use and which are linked to CMS provision. Both survey responses and supporting material were presented and discussed at three peer learning events, helping to go beyond mapping existing policies and practices to a more in-depth analysis of the shared understanding around CMS, of the diversity of ways in which such skills are being valued and fostered, and of significant gaps. In particular, the Europe-wide forum provided by the ELGPN afforded rich possibilities for critical reflection with a view to addressing policy-related issues in the area, especially in a period marked by a serious economic downturn. In the sections that follow, I draw on the range of material generated within the ELGPN activities, focusing in particular on the 
responses to the first survey, and supplementing that, where necessary, with insights developed from the second, special target-group survey, as well as the Europe-wide reviews referred to earlier.

\section{Defining career management skills}

Definitions of CMS vary across EU member states. This is evident not only from the ELGPN survey data, but also from the way in which the 2008 Lifelong Guidance Resolution paragraph on CMS has been translated into different languages. It is clear that CMS is a particularly Anglo-Saxon term in origin. The French translation 'acquisition de la capacité de s'orienter', which overlaps with the notion of 'self-guidance', seems to capture the notion of CMS, and several renderings of the relevant paragraph in the resolution appear to have followed the French way of articulating it. In some cases, however, the translations found it difficult to capture the concept as covered by the English and French semantic fields.

There is some concern, therefore, about the challenge of developing a shared, Europe-wide understanding of what is being referred to by CMS, particularly since none of the countries that responded to the ELGPN survey reported any specific attempt to use the term in their national context, let alone to formally define it. Several (e.g. Slovenia and Sweden) consider aspects of CMS within broader forms of 'career education' and 'career development learning', including 'lifeskills' or 'personal and social education'. Some restrict its meaning to narrower tasks such as 'career planning', 'transition skills', and 'job-search skills'. While there is a strong conceptual connectivity between all these terms in use, trans-national work requires stabilisation of some of the key meanings around CMS. The goal is not 'harmonisation' as much as improved mutual understanding: different terms in use reflect different approaches and underpinning philosophies, anchored in national or regional histories and cultures which should be acknowledged and valued.

Furthermore, while most European countries share the challenge posed by ailing economic performance, there are important labour market specificities that manifest themselves in the relative employment patterns and the nature and extent of opportunities for youths and adults. This is bound to result in diverse priorities when it comes to the importance accorded to CMS, how they are defined, and when and where implemented. CMS content too might reflect challenges specific to context, so that countries with low female participation in labour markets, or with a burgeoning part-time and temporary work sector, to mention just two examples, might reflect different priorities to those adopted in a country with a different employment profile. Similarly, eastern and central European countries will tend to approach career guidance and CMS from a somewhat different perspective, given their particular economic, political and cultural history (see Sultana 2007a). There are important differences too, between small and large state contexts (Sultana 2010). While this 
paper, given its synthetic aspirations, tends to identify and emphasise general trends across Europe, one must not lose sight of the very real differences not only between countries, but also within them as well.

One of the tensions around the use of the term 'CMS' refers to its apparent focus on work-related aspects of a person's development. Broader terms such as 'lifeskills' or 'Personal and Social Education' (PSE) more explicitly encourage a more life-wide approach which includes, but is not restricted to, employment - though of course, the term 'career' is also commonly used in the UK, North America, Australia and New Zealand to apply to wider forms of work, and includes learning too. As Austria, Finland and Lithuania noted in their survey response, adopting the more generic terms could be strategically wiser because these made the target competences 'more visible' to students and parents alike, since they are easier to understand. The Malta experience however signals some dangers in this. Here, career-related issues were, over time, elbowed out of the PSE curriculum in schools. For a number of reasons - not least because psycho-social problems among students are perceived to be on the increase - many PSE teachers have tended to privilege the personal dimensions in the PSE curriculum, rather than the themes linked to career development issues. Discussions among ELGPN members indicated that similar dynamics prevail in other countries. Indeed, the European guidance reviews showed that countries where personal counselling and career guidance services were offered by the same staff, the former often took precedence over the latter (Sultana 2004).

A definition that seems to capture the range of meanings that were attributed to CMS by survey respondents is the following:

Career management skills refer to a whole range of competences which provide structured ways for individuals and groups to gather, analyse, synthesise and organise self, educational and occupational information, as well as the skills to make and implement decisions and transitions.

CMS, therefore, aims to develop resources and competences in people to better manage their life course, or, to cite the Italian survey response, 'to become protagonists of their life project' - a particularly apt aspiration/metaphor given the implications of 'protean', 'boundaryless', 'portfolio' careers (Arthur and Rousseau 1996; Hall and Moss 1998). It is important to note that, even if, for stylistic reasons, the terms 'skills' and 'competences' are, in the context of this paper, used interchangeably, the notion of 'competence' implies more than mere 'skill' or 'knowledge', but involves values and attitudes as well (Sultana 2009a). It is this understanding of the term that underpins the European reference framework of key competences for lifelong learning (European Communities 2007; see also Table 1), and which - as the discussions within the ELGPN working group suggest - is in tune with educational philosophies currently prevalent in such countries as Austria, the Czech Republic, Italy and France, for instance, where reductionist and technicist approaches to learning and development are contested. 
Table 1. Mapping CMS within the European reference framework of key competences for lifelong learning.

Domains of the European reference framework of key competences for lifelong learning Links to CMS
(1) Communication in mother tongue
- Able to search, collect, process written information
- Able to distinguish relevant from irrelevant
(2) Communication in a foreign data language
- Able to work with diversity
(3) Math, science, technological literacy
- Able to manage a budget
- Cultivating a disposition towards critical thinking
- Able to manipulate tools and data to reach a conclusion
(4) Digital competence
- Able to use Internet-based data and services
- Able to use ICT to support critical thinking, creativity and innovation at leisure and work
(5) Learning-to-learn
- Effective self-management of learning and careers
(6) Interpersonal and civic competences
- Able to interact effectively with institutions
- Able to distinguish between work and personal life
(7) Entrepreneurship
- Skills in project development, implementation
- Able to identify one's strengths and weaknesses
- Able to assess and take risks when warranted
(8) Cultural expression
- Able to realise economic opportunities in cultural activities

Despite difficulties that some countries have with the term 'CMS', there nevertheless seems to be a high degree of shared understanding across Europe - evident in the survey responses, in the thematic work group and plenary ELGPN discussions, in the analysis of CMS-related curricular documents submitted by a range of ELGPN participants, and in the follow-up activities in national, regional and trans-European workshops and conferences - of what constitutes CMS content or a CMS curriculum. Most of the CMS-related programmes taught within schools and in PES contexts in the countries that responded to the survey cover themes that easily fall within the DOTS framework (Law and Watts 1977; Law 1999) - i.e. they involve learning competences that support decision-learning, opportunity awareness, transition learning and self-awareness. They also overlap with the themes which, in the 
Canadian Blueprint for Life/Work Designs (Jarvis 2003; National Life/Work Centre n.d.) - one of the better known CMS frameworks - are organised around three main categories, namely:

- 'personal management' (e.g. build and maintain a positive self-image; understand the influence of self-image on one's life and work; develop abilities for building positive relationships in one's life; learn to respond to change and growth; develop strategies for responding to life and work changes).

- 'exploring learning' (e.g. participate in life-long learning supportive of life/work goals; link lifelong learning to one's career building process; locate, interpret, evaluate and effectively use life/work information; understand the relationship between work and society/economy, and how societal and economic needs influence the nature and structure of work).

- 'work', and 'life/work building' (e.g. develop abilities to seek and obtain/create work; explore and improve decision-making; recognise and take charge of one's life/work-building process; explore and understand the interrelationship of life roles; link lifestyles and life stages to life/ work building; incorporate the 'balanced life/work' issue in life/work building; explore non-traditional life/work scenarios; understand and learn to overcome stereotypes in life/work building).

None of these are 'vocational' skills in the strict sense of the term; such skills fall outside the focus of CMS programmes. Rather, the latter target the development of generic reflexive aptitudes that support individuals in understanding self-in-context, in making decisions regarding education, training and work pathways, and in fostering self-efficacy. Most CMS programmes cover much the same topics and themes, with the main difference being, as we shall see in another section of this paper, in the way (and the extent to which) the competences are: (1) organised and packaged together to constitute a coherent and structured framework; and (2) integrated in curricula and learning programmes.

\section{The rationale underpinning CMS}

Across most countries surveyed, two linked rationales seem to underpin the interest in promoting CMS. The latter are seen to increase employability, and to thus promote social equity and inclusion. This focus also comes through the broader European reviews of career guidance, and in some of the CMS literature that is currently available in Europe (e.g. Arnold 2003; King 2004; Watts 2006). At school level, curricula have been or are being developed in order to help young people become more adept at planning and managing their transitions between education, training and employment. The survey responses indicate that the Czech Republic, for instance, has recently integrated work-related 
thematic areas into existing subject matter in the curriculum, while Austria, Lithuania, Malta and the Netherlands, to mention only four other examples, report an increasing emphasis being placed on preparing young people for the world of work. CMS are also taught to unemployed people, with many PES delivering or outsourcing innovative programmes that build employability skills in adults, with a view to increasing their chances of integration in a tight labour market (Sultana and Watts 2006a, 2006b).

An important justification for introducing or strengthening CMS is a greater awareness of the need for skills in managing one's non-linear career pathways in knowledge-based economies, where relatively frequent job changes are likely to take place (Herr 2008; Inkson and Elkin 2008). Some countries have clearly articulated their vision for CMS in relation to the changing world of work, aiming for a skills strategy that encourages competitiveness. Foremost among these is UK-Scotland, with its 'Curriculum for Excellence' initiative (Learning and Teaching Scotland n.d.). Other countries, such as Austria (the 'key2success' strategy - Schulpsychologie Bildungsberatung n.d.), France and the Netherlands, reported a process that entails the mapping of a series of CMS in relation to the European reference framework of key competences for lifelong learning, referred to earlier (European Communities 2007). This seems to be a particularly interesting strategy from a policy perspective, since the value of CMS is likely to be enhanced if seen within a broader curricular framework that has Europe-wide relevance and legitimacy. Table 1 shows how a number of CMS elements can be embedded in the lifelong learning European Reference Framework.

It is worth highlighting a tension in the increasing attention being placed on CMS on the one hand, and the decreasing opportunities for employment and especially for 'decent work' (Sennett 1998) - on the other. Indeed, historically, the bonds between education, training and employment have tended to be tightened during times of recession (Watts 1983; Carnoy and Levin 1995; Grubb and Lazerson 2004). The emphasis on CMS can, in some ways, be seen as a reflection of this historic trend. There is a danger in this, in that while the intention behind the development of CMS can indeed be to increase employability and to enhance equity and social inclusion, the unintended sub-text could be that those who end up out of work have only (or mainly) themselves to blame.

This trend towards 'responsibilisation' (Ball 2008) and 'individualization' of social issues (also vehicled by such terms as 'career resilience' and 'career agility') alerts us to the process of 'insourcing' (Lash 2003), i.e. a reallocation of functions, activities and responsibilities to the individual that were previously regarded as primarily the responsibility of institutions and collectives (Watts 1996). Such a trend is particularly worrisome since it is taking place at a time when notions of social solidarity are being weakened. 'Negative globalization' (Bauman 2006) has simultaneously reduced the power of the state, and provided it with complex, often bewildering challenges that it is ill-equipped 
to handle through the legal and institutional instruments that have been developed throughout its 200-year-old history. The state thus finds itself unable to offer security to its citizens, and obliged to call for more 'flexibility' in the labour market and in all other areas of life regulated by market forces. This means even more insecurity, and an increase in risk (Beck 2006). CMS, unless critically approached, can easily become yet another way by means of which the state reframes its deficit by projecting it as personal failing, with the victim blamed for problems that are structural in nature.

One can accordingly distinguish CMS approaches that focus on presumed individual deficits, and those that acknowledge that individual achievement (including employment) is strongly defined by the strength or otherwise of the economic environment. One way of articulating this is by noting the difference between CMS curricula that stress 'learning for work' (where individuals have to learn coping skills to adapt to a situation), and 'learning about work', where the focus is on a critical understanding of oneself in context (Simon, Dippo, and Schenke 1991). Survey responses suggest that Austria, Denmark, Finland and France - among others - seem to favour the latter approach, though it would be probably true to say that, in the implementation of CMS programmes, both orientations are present and are not necessarily seen as mutually exclusive, with the emphasis on pragmatism, 'realism' and 'fitting in' more likely to prevail in programmes delivered in labour market settings such as the PES (Sultana and Watts 2006a, 2006b).

Stressing CMS could also inadvertently lead to the blanket portrayal of young people as deficient in lifeskills. There is a danger, therefore, of failing to acknowledge the richly textured lives of individuals, all of whom will have, formally or informally, built up a range of CMS as part of their everyday experiences - experiences that relate to their class, gender and ethnic background. Many young people have already worked in part-time, after-school and summer jobs, and as a result will have developed several insights as well as knowledge, skills and attitudes through their interaction with peers and adults in a variety of contexts within and outside of formal institutions. The assumption must therefore not be made that young people come to CMS with a 'tabula rasa', but rather that CMS can in fact help students and adults become aware of what they already know and to build on that in self-reflective ways - a process that broadens and deepens learning through the acquisition of 'metacognitive skills' (i.e. self-awareness regarding learning, and capacity to reflect on it - see King 2004; Santrock 2007). The ELGPN surveys indicate that Denmark, Finland and France are fostering the development of such metacognitive skills through the use of CMS reflective portfolios.

Young people should also not be considered to be 'empty slates' because curricular traditions and learning programme development in a number of countries strongly emphasise the importance of a 'relevant curriculum', with major efforts being made to link education to life tasks and concerns. From their perspective, the notion of CMS as a distinct focus in or through the curriculum 
operates within an assumption that schools fail to prepare students for life, and that they therefore need a 'compensatory programme' to make up for that deficit. While this may very well be true in some education systems, it is not necessarily true or equally applicable across the board. For some countries more than for others, CMS are - or should be - an outcome of the regular curriculum, also implying that at least some of the competences in question are 'caught', rather than 'taught'. As the ELGPN surveys showed, the Austrian approach is especially relevant here, given the conviction that education cannot teach competences as much as it can provide rich, varied and pedagogically appropriate experiences and environments that facilitate their development.

It is therefore important to acknowledge and work with the tensions that are present in the discourse surrounding CMS. Awareness of the issues that have been identified above is not new. There is indeed a long research tradition that is critical of several aspects of CMS/lifeskills-type curricula, and particularly of programmes which, like those developed by Hopson and Scally (1980), are informed rather more by humanistic individualism than by a structural and political approach. The critique levelled within the latter tradition highlights the ways in which problems relating to the individuals' interactions with the labour market are structural problems with the demand side and therefore require structural solutions, while CMS/lifeskills-type programmes tend to construct these problems as susceptible to solution through individual agency by targeting the supply side. This research tradition was especially vibrant and influential during the recession of the 1980s, and resonates with the concerns that are emerging during the current economic downturn. In Thatcherite Britain, several CMS-type programmes were developed by the Manpower Services Commission to facilitate the transition of young people into employment. A number of authors (inter alia Atkinson et al. 1982; Gleeson 1983; Bates et al. 1984; Dale 1985) were quick to argue that such 'Youth Opportunity Programmes' were nothing more than a thinly veiled attempt at exporting intractable economic problems onto young people No amount of 'editing' of the self (through learning typical such career management competences as selfpresentation and interviewing skills, for instance) would clinch a job (Cathcart and Esland 1985), and at best would only serve to shuffle the position of individuals in the dole queue. Similar critiques were mounted in Canada (Gaskell 1986; Simon, Dippo, and Schenke 1991), Australia (Wilson and Wyn 1983; Dwyer, Wilson, and Woock 1984), and New Zealand (Korndorffer 1987; Sultana 1989).

While the CMS thematic working group was generally sympathetic to such critiques, there was also a shared understanding that, beyond the language of critique one needs to engage with a language of possibility, and that CMS could potentially provide critical educators with a wealth of opportunities to help young people and adults understand how the world of work functions, how to engage with it in ways that lead to self-development and fulfilment, how to de-code and contest exploitative strategies, and how to recognise and 
contest limitations imposed by gender, ethnic and other forms of stereotypes (Irving 2010). As we shall note, some of these competences are more easily taught than others, and many are best learnt when embedded in a curriculum rather in disconnected ways. The thesis is that, given the centrality of work in people's lives, it is crucial that all citizens are equipped with the discretionary knowledge that helps them make sense of their working lives, and to have as much informed control over that as possible. CMS programmes, when conceived in this manner, and when they are not hijacked and shaped by business interests - as they have tended to be within junior achievement, for instance (Sukarieh and Tannock 2009) - can potentially be a source of empowerment rather than of domestication.

While CMS programmes embody a number of tensions, and indeed may be viewed differently across Europe, both the ELGPN surveys and the wider EU reviews suggest that there nevertheless is a policy consensus that the development of 'career learning' can be useful and positive, and that the Council Resolutions inviting member states to make CMS the subject of focused attention are timely. Two further comments need to be made at this point. First, it is important to note that such consensus is evident at the policy-making level in the main, and might not necessarily be shared to the same extent by other communities of practice where, as we have noted in the case of critical researchers, there remains a degree of wariness at the way the links between education, training and work are articulated. Such policy consensus is evident given the number of countries that report making progress in integrating CMS, particularly at the secondary and higher education levels (see for instance Watts 2006; Bridgstock 2009; Learning and Skills Improvement Service 2009). In the labour market sector, PES focus on the 'activation' of unemployed and the shift from 'welfare' to 'workfare' policies (Lødemel and Trickey 2001) has led to a range of initiatives that support the job-search process through the delivery of CMS training (Sultana and Watts 2006a, 2006b). A distinction can be drawn between the preventive approach that tends to mark CMS delivered in schools, and the dominant curative approach of CMS in the labour market sector. Economic arguments could probably be made showing the cost-effectiveness of 'prevention' over 'intervention'.

A second point is that, despite policy-level consensus across Europe and beyond that there is much to be gained by integrating CMS in school curricula and in PES welfare to work programmes - there is as yet little in the way of hard evidence to back up such optimism. While it is not unreasonable to assume that individuals benefit from programmes that help them better understand themselves and their relationship to the changing world of work, much research still needs to be carried out to evaluate the impact of CMS on, for instance, measures of self-efficacy and on more reflexive approaches to the construction of one's occupational pathways (learning and behavioural outcomes), or on improved rates of job placements and on increased satisfaction at work (economic and social outcomes). Recently, the whole career guidance field has 
been engaged in examining the extent to which its interventions are, indeed, 'productive' (Watts and Dent 2006) - not least because policy-makers need evidence to justify investment of public money in services, particularly in times of recession, and in the face of growing demand (Sultana 2008). The 'evidence base' is gradually being built up (see, inter alia, the work of Whiston, Sexton, and Lasoff 1998; Morris, Golden, and Lines 1999; Prideaux et al. 2000; Mayston 2002), but more work needs to be done specifically in relation to the impact of CMS - a point that will be reiterated in the conclusion to this paper.

\section{Implementing the CMS curriculum in the education sector}

Despite the lack of sufficiently robust evidence in support of the presumed benefits of CMS, the reviews of career guidance as well as the ELGPN mapping surveys suggest that CMS-type programmes are increasingly present in education systems across Europe. CMS are typically integrated in the curriculum in one of four ways. They can be taught as a separate subject. Examples here include Austria and Malta, which offer a PSE curriculum. Other countries dedicate time specifically to career education. In some cases as in France and Slovakia, for instance - the subject is optional, and available only for particular year groups. Some countries, such as Estonia, France, Lithuania, the Netherlands and the UK, reported that they offer stand-alone CMS courses at the higher education level, with some universities awarding students academic credit for participating. At school level, several countries have experienced a curriculum overload, with new knowledge areas - such as ICT - placing pressure on an already crammed school timetable. The likelihood of prising open a separate curricular space for CMS is therefore small.

Despite the difficulties involved, it is worth noting some advantages with this approach. CMS as a separate, timetabled subject promotes a clear focus facilitating curriculum development and curriculum delivery, with teaching (in some cases) being carried out by specialised staff. A disadvantage is that career learning can be seen as a somewhat separate topic, unrelated to linked life concerns. Another challenge concerns student motivation for the 'subject': in many cases, CMS learning is not examined, though learning may be assessed informally (e.g. through portfolios). In examination-oriented systems, the lack of a formal assessment may give students the message that CMS is not an important subject within the curriculum, with a consequent drop in motivation for it - a concern that was expressed in different ways by several members of the ELGPN thematic work group.

CMS can feature as a compulsory theme across the curriculum - what is sometimes referred to as the 'curriculum infusion' model or approach (OECD 2004). Examples generated by the ELGPN survey include the Czech Republic (through set themes that are integrated within established subject areas such as economics, Czech language, civic education and so on), Estonia (which has established service standards to ensure that a minimum amount of time is 
dedicated to the area across the curriculum in all schools), and Sweden. This approach can promote greater integration of CMS within other aspects of the curriculum, and makes career learning a concern for several teachers rather than only for those who are employed to teach it as a separate subject.

The success of the CMS programme within this approach depends on whether or not teachers are keen and able to integrate career learning in their respective subjects, and whether or not they have been trained to do so. With regard to the former, Watts (2001) highlights the difficulties of infusing CMS themes into traditional subjects based on very different 'recognition rules' (Whitty, Rowe, and Aggleton 1994), i.e. rules about what teachers and pupils regard as legitimate discourse within particular lessons. Another challenge is to ensure that students are able to identify the CMS elements integrated in a range of subjects, and to make links between the career development learning acquired across the curriculum. Austria provides a useful example of how this purposeful learning could be enhanced: CMS-related items have been mapped across the curriculum, and a teachers' handbook highlights the CMS elements that are being taught in different areas of study. This facilitates teacher collaboration in planning effective curriculum delivery, since they are more likely to see it as a co-shared task. It also helps make CMS learning more visible to students, who are consequently enabled to make the link between different inputs by different teachers, weaving together the career development learning in purposeful and self-reflective ways through building up a portfolio. Denmark - through its 'log book' - and France - through its 'livret personnel de suivi' and 'webclasseur' initiatives - also ensure curriculum integration and purposeful student reflection on CMS-related learning, which might otherwise remain dispersed. In the best of cases, the insights generated by such reflection are shared and discussed with career advisers, and also with parents.

CMS can be taught through extra-curricular activities, including, for instance, CMS workshops delivered at key transition points, such as when students are about to leave the compulsory education sector. As the ELGPN survey shows, France has gone some way in formalising such career guidancerelated activities, with a mix of initiatives that are sometimes within, sometimes outside the regular curriculum in order to make sure that at key stages throughout a student's life, there are intensified periods of reflection on developmentally appropriate CMS-related issues. The French example suggests that powerful learning environments can be created when such extra-curricular activities are well organised, are underpinned by a strong conceptual rationale, and are linked to a range of well-resourced activities. Another advantage of CMS programmes delivered in this manner is that they can be easily tailored to target specific groups, such as students with disabilities, for instance. In many countries, however, such workshops and seminars are organised on an ad hoc basis, and while useful, could give the message that CMS are insufficiently relevant and important to be integrated in the mainstream curriculum. This form of CMS delivery may also suffer from being 'too little, too late': the 
competences cannot be covered in depth, and are offered when students, in many cases, have already made preliminary decisions about work and further education and training.

The ELGPN surveys indicate that in some countries (e.g. Austria, Finland, France and Malta), we find a mix of two or all three of the above, often in an effort to capitalise on the usefulness of the respective approaches. Students can thus be exposed to the CMS curriculum in a variety of ways, at different points throughout their passage through school, possibly with more intensity of coverage and focus at key transition points. A key issue here is the question of overlap and repetition: this can be constructive and educationally meaningful if planned, an outcome that requires high levels of coordination between teachers, which is more likely to be present in some education systems - such as Austria and Finland - where teacher cooperation and school-based curriculum development are highly prized.

Finally, it should be noted that in some cases, schools are attempting to diversify the mode of delivery of CMS by breaking the boundaries that separate the school from the rest of the students' lives. They are doing this in at least three ways. Firstly, schools are increasingly taking into account the fact that much of the learning actually takes place outside the formal education system. Careers Scotland, for instance, has made strategic alliances with youth and community-based organisations (such as the Girl Guides), and trained some of the leaders there to deliver CMS-related content. Secondly, as in Portugal, Slovakia, Slovenia and Sweden, outside agencies are invited to the school to deliver the more specialised aspects of CMS. Thirdly, the opportunities provided by ICT are being increasingly exploited to change the usual delivery paradigm. Careers Scotland, for instance, is making good use of webcasts, video conferencing and social networking facilities such as 'Facebook' to ensure 24/7 access. Some countries are also considering the award of a credit voucher to students so that they can purchase the career management support they need from any service provider they choose.

Each of these different approaches has major implications for the way the roles of career guidance staff are defined, for the range of staff profiles that are required (e.g. 'class masters' or 'form teachers', CG adviser, subject area coordinator, head of department, principal), and for the training that such staff should receive in order to deliver CMS either as a separate subject, as embedded in a range of subject areas, or/and as an extra-curricular activity. They also have implications for the pedagogy used to facilitate learning CMS, and the way such learning is assessed.

\section{Teaching and assessing}

When it comes to pedagogical methods used to teach CMS, most countries involved in the ELGPN surveys emphasise multidimensional approaches, involving not only instruction, but also counselling, a range of experiential 
learning strategies (e.g. role play, work shadowing and work experience, case studies), career games, computer-based resources, and so on. Indeed, CMS is seen by some to be an opportunity to bring about a paradigm shift in the way learning is organised in schools, with a greater degree of emphasis on supporting student self-directed learning, active learning methods and constructivist approaches to meaning-making (Sultana 1997; Hooley et al., forthcoming).

The assessment of CMS learning does not seem to be high on the agenda of the countries surveyed, though a strong case underscoring the need for that has been made by Barnes (2009), among others. Most privilege non-formal, continuous and formative assessment strategies. Portfolios, whether paper- or web-based, are used in Austria, Denmark, Finland, France and UK-Scotland. Variants of portfolios, which similarly encourage self-reflection, are used in several other countries. The notion of having a personal workbook which accompanies students till they leave school seems particularly promising, helping as it does to make tacit knowledge explicit. In France, this 'carnet de route' is shared with teachers and parents, thus providing students with support in making sense of the career learning developed along the way. In many cases, multimodal forms of assessment are being used, reflecting the broader evaluation culture embedded in the national education system. These include formal examinations, oral interviews, self-assessment, continuous assessment and competence-based assessment - such as when students are required to articulate their own action plan, drawing on the CMS they have learnt.

\section{Implementing CMS in the labour market sector}

ELGPN survey data are less rich when it comes to CMS programmes in the labour market sector, though a number of initiatives were recorded in the review made of PES across Europe (Sultana and Watts 2006a, 2006b), and additional trends can be gleaned from other studies (e.g. Thuy, Hansen, and Price 2001). Despite the paucity of material in hand, some issues deserve to be highlighted. First, it seems clear that CMS as offered through PES can be characterised in a number of ways: programmes tend to be: (1) short-term in orientation (i.e. to enhance immediate employment rather than employability, and hence 'curative' and compensatory in orientation); (2) disconnected from previous input in schools (i.e. the assumption is often made that clients do not bring with them useful CMS learnt at school); and (3) customised for target groups (often those considered 'at risk').

The range of activities that fall within the CMS ambit are varied, but can be bundled within the personal action planning approach. This focuses on motivating and 'activating' clients, and on increasing their goal-orientation and sense of self-efficacy - a key target of the European Employment Strategy and of the European Employment Guidelines (Commission of the European Communities 2005). The Lithuanian Labour Market Training Authority, for instance, provides a typical example of the work that is generally carried out 
by many PES across Europe. Lithuanian staff help individuals and groups develop vocational decision-making skills (e.g. self-awareness, selfdirectedness, knowing about occupational opportunities, career planning); employment skills (e.g. overcoming anxiety and stress, making contacts, establishing influence, manage conflicts); and self-confidence (e.g. strengthening positive attitude, positive evaluation of one's abilities, formulating attainable goals, learning how to overcome obstacles). Like their counterparts in the EU, Lithuanian staff make use of a whole variety of methods to facilitate the development of such CMS, including lectures, discussions, tests, success factor analysis, self-analysis, relaxation and self-help exercises, individual counselling, role play, and so on.

The rationale underpinning CMS delivery in PES contexts is also varied, and can be characterised as having, as a goal, the desire to 'entice' (i.e. 'activate' the unemployed and motivate them to engage in behaviour that is more likely to lead to employment); to 'enable' (i.e. to provide skills that consolidate the job search process of already motivated individuals); to 'empower' (i.e. to enhance employability, but within a learning context that acknowledges that unemployment is the outcome of economic and environmental factors, not merely or primarily individual deficits); and to 'enforce' (i.e. the learning of CMS is made a condition to access welfare benefits). While services will typically exhibit a mix of these competing orientations, where the emphasis is placed will have important consequences for programme design, for programme delivery, and for programme outcomes.

The principles underlying CMS programme development in the labour market sector are similarly diverse. However, as the review of PES across Europe showed, there is a tendency for them to be decentralised (i.e. developed at the local level of the service provider), to be offered in partnership with other agencies (i.e. often through outsourcing to service providers that are close to the client group), to be customised (i.e. following the principle of the personalisation of services adopted by European PES, and thus tailor-made to the specific needs of particular groups), and to be outcome-oriented (i.e. with a view to enhancing placement).

\section{Curricular frameworks for CMS}

While many European countries have integrated - or are in the process of integrating - CMS in both the education and labour market sectors, we do not find, in Europe, a formal framework that organises CMS learning in a structured manner across the lifespan, in the same way and to the same extent as in the USA, Canada and Australia. At best, the ELGPN surveys suggest that some efforts have been made by a few countries to indicate the kinds of CMS themes that can be addressed by teachers within compulsory and/or higher education contexts. This is the case with the Czech Republic, for instance, as well as with Austria, Malta and the UK. Few, however, have 
designed a well-thought-through framework that is underpinned by a developmental rationale (i.e. what should be taught, at what level, when), or by an overtly articulated theory of learning (which in the Canadian Blueprint is organised around four levels of deepening skills development, i.e. acquisition, application, personalisation and actualisation).

One of the reasons for the lack of such a formal framework may be the trend in some countries - particularly in Central and Eastern Europe, but elsewhere as well - to decentralise their education systems. This has given schools a degree of autonomy in deciding what should be included in the curriculum, leading to divergences between different schools. A number of curricular choices therefore depend on what the principal and the teaching community value. While this has some advantages in ensuring curriculum relevance within specific contexts, it also can lead to some problems. It is for instance difficult to determine, at a national level, how much time is being dedicated to particular areas such as CMS. In some cases, as in Denmark, for instance, the lack of a national or regional framework has led to situations where publishers take the lead in developing teaching resources, with textbooks produced automatically becoming 'the curriculum', given the tendency of teachers to teach to the text.

A good example of a CMS programme that is underpinned by clear curriculum development principles is provided by UK-Scotland, though UKEngland's national framework of learning outcomes for career education and guidance catering for students from age 11 to age 19 (Department for Education and Skills 2003), and Finland's recent national curriculum, which gives specific attention to career guidance issues, are also of interest.

In Scotland, the principles informing the 'Curriculum for Excellence' (Learning and Teaching Scotland n.d.) include: challenge and enjoyment, breadth, progression, depth, personalisation and choice, coherence, and relevance. While these principles have curriculum-wide applicability, they are also relevant for those areas linked to CMS, and shape the way such competences are integrated and delivered. Other principles that could be relevant to the development of a CMS curriculum, include: (1) vertical and horizontal integration with other subject areas; (2) customisation in response to differentiated learner needs and to economic challenges within specific contexts; and (3) 'centralised decentralisation', which tries to draw benefits from a national framework that still permits flexible implementation at the school level.

\section{A European CMS framework?}

One way of stimulating the development of national curricular frameworks is by promoting the emulation of those that already exist. The US National Career Development Guidelines of 1988, for instance, inspired the development of the Canadian Blueprint of 1998, which in turn was the basis for the Australian Blueprint for Career Development of 2008. The ELGPN thematic work group considered these initiatives, and reflected on the possibility of 
defining a 'blueprint' which would be widely applicable to EU member states. It was soon discovered that the development of supra-national curricular frameworks faces a number of challenges, particularly in a region whose constituent countries have diverse education and training traditions, of which they are justifiably proud.

The notion of a 'Blueprint', let alone a 'European Blueprint', gives the unfortunate impression that there is 'one best way' of doing things, that a degree of harmonisation between diverse education and training systems is possible, and that policies and practices can be lent and borrowed unproblematically. Several comparative studies have shown that nothing could be further from the truth (Steiner-Khamsi 2004). Formal educational practices are filtered through national curricular and institutional cultures and traditions, which are deeply intertwined with a country's or a region's history (Alexander 2001). It has been postulated, for instance, that there are at least three distinct curricular traditions across Europe (see McLean 1990), namely the Encyclopaedic tradition (content-oriented, and typical of France), the Humboldt tradition (humanist and process-oriented, with roots in the German notion of 'bildung'), and the Anglo-Saxon tradition (which has a strong emphasis on pastoral care, but which is increasingly outcome-oriented). Any curricular innovation is shaped by these different cultures, and is understood, defined and implemented within the logic of historically embedded practices. These contexts determine the view of the learner (e.g. as active or passive, as 'tabula rasa' or as co-constructor of knowledge), the role of the state (e.g. in terms of the degree of centralised, national curricular frameworks, in contrast to an emphasis on subsidiarity), the preferred pedagogic and assessment approaches (e.g. examination-oriented systems with national concours, in contrast to formative and continuous assessment styles), and so on. For these reasons, any attempt to either adopt or adapt a 'blueprint', and even more to establish it as a Europe-wide curricular 'reference framework', is bound to run into difficulties.

The Lithuanian case study reported to the ELGPN thematic work group illustrates this very well: Lithuania tried to adopt and adapt the Canadian Blueprint, but encountered serious problems given that the concepts and practices informing the Blueprint - which were often assumed rather than overtly expressed - clashed with Lithuanian educational traditions, and with local understandings of terms and of career development theories. While, therefore, the Blueprint had appeared to be an attractive and practical model, an off-theshelf solution to national aspirations to develop a CMS curriculum, it was soon discovered that there were disagreements with underpinning philosophies, concepts and practices, and that what initially appeared to be an easily assimilative model had, in fact, a strong specificity to it linked to the context in which it was developed. While countries can learn from each other's experiences, and while globalisation and Europeanisation forces may be intensifying homogeneity and convergence in a range of areas, the specificity of contexts cannot be ignored (Green, Wolf, and Leney 1999). 


\section{Addressing gaps and ways forward}

The lack of curricular frameworks is an important lacuna in the development of CMS in Europe - but it is not the only gap. Three other issues deserve to be highlighted in this context. First, and as already noted, while the case for CMS is relatively strong at the conceptual level, there is the need for more robust empirical evidence to support claims that CMS programmes are effective in improving employability - or even that they are transferable from the school contexts where they are learnt, to out-of-school contexts. Measurable outcomes are important for policy-makers, especially in a resource-impoverished environment where tough decisions have to be made when choosing which initiatives to fund. Policy support for CMS programmes in both educational and labour market settings is more likely to be forthcoming if evidence shows that such programmes do make a difference in terms of one or more of the outcomes identified by the OECD (2004) - namely learning, behavioural and longer-term outcomes.

A second gap in the current deliberation on CMS in Europe is the lack of adequate attention to the training of those who are teaching the skills. Current conceptualisations of CMS require teachers and trainers to have a broad range of abilities: school teachers, for instances, need to work with colleagues including career guidance advisers - in order to develop and deliver CMS across the curriculum. Some CMS programmes require teachers to work with out-of-school partners, whether from the PES or from youth agencies and community organisations. Teachers are also expected to teach CMS through a whole range of active learning methods, and to assess learning in innovative ways. A policy focus on service provider training for CMS delivery and evaluation seems warranted.

Thirdly, much of the discourse around CMS tends to be guided by a rather undifferentiated view of the learner to whom the CMS programme is addressed. A key challenge for those facilitating career learning is to ensure that they remain sensitive - and effectively respond - to diversity in all its forms. The ELGPN's second survey focused specifically on the extent to which CMS content and delivery modes are being tailored to cater for clients who are differentiated along a range of factors, including special needs, ethnicity and culture, gender, class, and so on. While there are several initiatives attempting to articulate a policy and service response in relation to so-called 'target groups', much work still needs to be done to identify the different CMS needs that arise out of specific life circumstances, and to generate specific CMS delivery modes that are more appropriate for such groups (Sultana 2009b). Work also needs to be done with regard to attending to learners' distinctive learning styles, whether or not they are categorised as being 'vulnerable', 'at risk', or needing special attention: some groups prefer activities that are more strongly structured, while others encounter difficulties in working with the individual ethos promoted by typical CMS strategies, such 
as when they are asked to draw up an individual education plan. Further work needs to be done to more comprehensively address the challenge of promoting CMS among a diversity of learners.

CMS are clearly high on the European policy agenda, and are generating a range of debates that have relevance beyond the region. However, the gaps and lacunae that have been identified above need to be effectively addressed if further progress in both policy and practice is to be attained. Such policies and practices need to remain sensitive to the different national labour market realities, as well as to the diverse curricular traditions across different countries, so as not to lose sight of the inherent problems of generic extrapolation of CMS provision to disparate contexts.

\section{Acknowledgements}

This paper is based on a number of unpublished studies commissioned by the European Lifelong Guidance Policy Network, and builds on survey data and materials submitted mainly by members of the CMS working group. Thanks are due to the latter, and to all ELGPN members - and particularly to A.G. Watts and Jasmin Muhič - who provided feedback on earlier drafts. Thanks are also due to the two anonymous referees whose feedback challenged me to think through some of the issues in more depth.

\section{Note}

1. The OECD survey instrument contains 12 sections, with several questions that a team of career guidance experts from each participating country were requested to address. The questionnaire, together with country reports, concept papers, and a range of other documentation, is available at http://www.oecd.org/document/20/ 0,3343,en_2649_39263294_32474452_1_1_1_1,00.html. The subsequent surveys by the European Commission and its agencies made use of the same survey instrument, modifying it slightly in consultation with career guidance specialists from the countries in which it was used. In some of the surveys, teams of at least two international experts paid a visit to the country concerned in order to supplement the questionnaire data through observations of career guidance service delivery, as well as interviews with policy-makers, service managers and practitioners.

\section{Notes on contributor}

Ronald G. Sultana is a professor of educational sociology and comparative education at the University of Malta, where he directs the Euro-Mediterranean Centre for Educational Research. He was a Fulbright fellow at Stanford University, and is a fellow of the National Institute of Career Education and Counselling, Cambridge. He has authored several studies on career guidance in the EU and in the Arab states.

\section{References}

Alexander, R. 2001. Culture and pedagogy: International comparisons in primary education. Oxford/Boston, MA: Blackwell.

Arnold, J. 2003. Managing careers into the 21st century. London: Paul Chapman. 
Arthur, M.B., and D.M. Rousseau, eds. 1996. The boundaryless career: A new employment principle for a new organizational era. Oxford: Oxford University Press.

Atkinson, P., T.L. Rees, D. Shone, and H. Williamson. 1982. Social and life skills: The latest case of compensatory education. In Youth unemployment and state intervention, ed. T.L. Rees and P. Atkinson, 125-33. London: Routledge/Kegan Paul.

Ball, S.J. 2008. The education debate: Policy and politics in the twenty-first century. Bristol: Policy Press.

Barnes, A. 2009. Assessment for career learning and development: Now or never? Career Education and Guidance, February 2-7. http://www.aceg.org.uk/ac_abt5 .pdf (accessed July 25, 2010).

Bates, I., J. Clarke, P. Cohen, D. Finn, R. Moore, and P. Willis. 1984. Schooling for the dole: The new vocationalism. London: Macmillan.

Bauman, Z. 2006. Liquid times: Living in an age of uncertainty. Cambridge: Polity Press.

Beck, U. 2006. Living in the world risk society. A Hobhouse memorial public lecture given at London School of Economics, February 15. http://www.libertysecurity. org/IMG/pdf_Beck-2006.pdf (accessed July 25, 2010).

Bridgstock, R. 2009. The graduate attributes we've overlooked: Enhancing graduate employability through career management skills. Higher Education Research and Development 29, no. 1: 31-44.

Carnoy, M., and H. Levin. 1995. Schooling and work in the democratic state. Stanford, CA: Stanford University Press.

Cathcart, H., and G. Esland. 1985. The compliant creative worker: The ideological reconstruction of the school leaver. In Education and social change, ed. L. Barton and S. Walker, 173-92. London: Croom Helm.

Commission of the European Communities. 2005. Cohesion policy in support of growth and jobs: Community strategic guidelines, 2007-2013. COM(2005) 0299, Brussels. http://ec.europa.eu/regional_policy/sources/docoffic/2007/osc/050706osc_en.pdf (accessed July 25, 2010).

Council of the European Union. 2004. Strengthening policies, systems and practices in the field of guidance throughout life in Europe. Document 9286/ 04 EDUC 89 SOC 234. http://ec.europa.eu/education/policies/2010/doc/resolution2004_en.pdf (accessed July 25, 2010).

Council of the European Union. 2008. Council Resolution on better integrating lifelong guidance into lifelong learning strategies. 2905th Education, Youth and Culture Council Meeting, Brussels, November 2008. http://www.consilium.europa.eu/ueDocs/cms_Data/docs/pressData/en/educ/104236.pdf (accessed July 25, 2010).

Dale, R., ed. 1985. Education, training and employment: Towards a new vocationalism? Oxford: Pergamon Press.

Department for Education and Skills. 2003. Careers education and guidance in England: A national framework 11-19. DfES/0163/2003. http://www.teachernet.gov.uk/_doc/6009/DFES-0163-2003.pdf (accessed July 25, 2010).

Dwyer, P.J., B. Wilson, and R. Woock. 1984. Confronting school and work. Sydney: Allen \& Unwin.

European Communities. 2007. Key competences for lifelong learning: European reference framework. Office for Official Publication of the European Communities, Luxembourg. http://ec.europa.eu/dgs/education_culture/publ/pdf/ll-learning/ keycomp_en.pdf (accessed July 25, 2010).

Gaskell, J. 1986. The changing organisation of business education in the high school: Teachers respond to school and work. Curriculum Inquiry, 16: 417-37. 
Gleeson, D., ed. 1983. Youth training and the search for work. London: Routledge/ Kegan Paul.

Green, A., A. Wolf, and T. Leney. 1999. Convergence and divergence in European education and training systems. London: Institute of Education.

Grubb, W.N., and M. Lazerson. 2004. The education gospel: The economic power of schooling. Harvard: Harvard University Press.

Hall, D.T., and J.E. Moss. 1998. The new protean career contract: Helping organizations and employees adapt. Organizational Dynamics 26, no. 3: 22-37.

Herr, E. 2008. Social contexts for career guidance throughout the world. In International handbook of career guidance, ed. J.A. Athanasou and R. Van Esbroeck, 45-67. New York: Springer.

Hooley, T., A.G. Watts, R.G. Sultana, and S. Neary. Forthcoming. Career management skills blueprint for Scotland. A series of 5 Working Papers for Skills Development Scotland.

Hopson, B., and M. Scally. 1980. Lifeskills teaching programmes. Leeds: Leeds University Printing Service.

Inkson, K., and G. Elkin. 2008. Landscape with travellers: The context of careers in developed nations. In International handbook of career guidance, ed. J.A. Athanasou and R. Van Esbroeck, 69-94. New York: Springer.

Irving, B.A. 2010. (Re)constructing career education as a socially just practice: An antipodean reflection. International Journal of Educational and Vocational Guidance 10, no. 1: 49-63.

Jarvis, P.S. 2003. Career management paradigm shift: Prosperity for citizens, windfalls for governments. http://www.contactpoint.ca/natcon-conat/2003/pdf/pdf-0315.pdf (accessed July 25, 2010).

King, Z. 2004. Career self-management: Its nature, causes and consequences. Journal of Vocational Behaviour 65: 112-33.

Korndorffer, W., ed. 1987. Transition: Perspectives on school-to-work in New Zealand. Palmerston North: Dunmore Press.

Lash, S. 2003. Reflexivity as non-linearity. Theory, Culture and Society 20, no. 2: 49-57.

Law, B. 1999. Career learning space: New DOTS thinking for careers education. British Journal of Guidance and Counselling 27, no. 1: 35-54.

Law, B., and A.G. Watts. 1977. Schools, careers and community. London: Church Information Office.

Learning and Skills Improvement Service. 2009. Career learning for the 21st century: The career blueprint - a competence approach. Coventry: Learning and Skills Improvement Service.

Learning and Teaching Scotland. n.d. Curriculum for excellence. http:/www.ltscotland.org.uk/curriculumforexcellence/index.asp (accessed July 25, 2010).

Lødemel, I., and H. Trickey. 2001. An offer you can't refuse: Workfare in international perspective. Bristol: Policy Press.

Mayston, D. 2002. Evaluating the benefits of career guidance. Derby: Centre for Guidance Studies, University of Derby.

McLean, M. 1990. Britain and a single market Europe. London: Kogan Page/The Institute of Education, University of London.

Morris, M., S. Golden, and A. Lines. 1999. The impact of careers education and guidance on transition at 16. RD 21. Sheffield: Department for Education and Employment.

National Life/Work Centre. n.d. Blueprint for life/work designs. http:// 206.191.51.163/blueprint/home.cfm (accessed July 25, 2010). 
Organisation for Economic Co-operation and Development (OECD). 2004. Career guidance and public policy: Bridging the gap. Paris: OECD.

Prideaux, L.-A., P.A. Creed, J. Muller, and W. Patton. 2000. A review of career interventions from an educational perspective: Have investigations shed any light? Swiss Journal of Psychology 59, no. 4: 227-39.

Santrock, J. 2007. Information processing: A topical approach to life-span development. New York: McGraw-Hill.

Schulpsychologie Bildungsberatung. n.d. key2success: Was tun nach der matura? http://key2success.schulpsychologie.at (accessed July 25, 2010).

Sennett, R. 1998. The corrosion of character: The personal consequences of work in the new capitalism. New York: W.W. Norton.

Simon, R., D.A. Dippo, and A. Schenke. 1991. Learning work: A critical pedagogy of work education. New York: Bergin \& Garvey.

Steiner-Khamsi, G., ed. 2004. The global politics of educational borrowing and lending. New York: Teachers College Press.

Sukarieh, M., and S. Tannock. 2009. Putting school commercialism in context: A global history of junior achievement worldwide. Journal of Education Policy 24, no. 6: 769-86.

Sultana, R.G. 1989. Transition education, student contestation and the production of meaning. British Journal of Sociology of Education 10, no. 3: 287-309.

Sultana, R.G. 1997. Personal and social education: Opportunities for work education. In Careers education and guidance in Malta: Issues and challenges, ed. R.G. Sultana and J.M. Sammut, 243-70. Malta: PEG.

Sultana, R.G. 2003. Career guidance policies in 11 acceding and candidate countries. Turin: (ETF European Training Foundation).

Sultana, R.G. 2004. Guidance policies in the learning society: Trends, challenges and responses across Europe. Thessaloniki: CEDEFOP.

Sultana, R.G. 2007a. Guiding learners in the learning society: The situation in nine Central and Eastern European countries. In A clash of transitions: Towards the learning society, ed. O. Strietska-Ilina, 205-42. New York: Peter Lang.

Sultana, R.G. 2007b. L'Europa e la sfida dell'orientamento professionale lungo tutto l'arco della vita [Europe and the challenge of lifelong career guidance]. Rassegna Cnos no.3 (Ottobre-Dicembre), 28-45.

Sultana, R.G. 2008. From policy to practice: A systemic change to lifelong guidance in Europe. Thessaloniki: CEDEFOP.

Sultana, R.G. 2009a. 'Competence' and 'competence frameworks' in career guidance: Complex and contested concepts. International Journal for Educational and Vocational Guidance 9, no. 4: 15-30.

Sultana, R.G. 2009b. Career management skills for special target groups: Policy issues for Europe. Unpublished concept paper prepared for the European Lifelong Guidance Policy Network.

Sultana, R.G. 2010. Chameleon careers? Exploring the specificity of career guidance in small states.' In Education in small states: Global imperatives, regional initiatives and local dilemmas, ed. P. Mayo, 13-143. London: Routledge.

Sultana, R.G., and A.G. Watts. 2006a. Career guidance in Europe's Public Employment Services: Trends and challenges. Brussels: DG Employment, Social Affairs and Equal Opportunities.

Sultana, R.G., and A.G. Watts. 2006b. Career guidance in Public Employment Services across Europe. International Journal for Educational and Vocational Guidance 6, no. 1: 29-46. 
Sultana, R.G., and A.G. Watts. 2007. Career guidance in the Mediterranean region. Turin: ETF.

Sultana, R.G., and A.G. Watts. 2008. Career guidance in the Middle East and North Africa. International Journal for Educational and Vocational Guidance 8, no. 1: 19-34.

Sweet, R. 2006. Career guidance in the Western Balkans region [mimeo]. Turin: ETF.

Thuy, P., E. Hansen, and D. Price. 2001. The Public Employment Service in a changing labour market. Geneva: International Labour Organisation.

Watts, A.G. 1983. Education, unemployment and the future of work. Milton Keynes: Open University Press.

Watts, A.G. 1996. Socio-political ideologies in guidance. In Rethinking career education and guidance: Theory, policy and practice, ed. R. Hawthorn, J.M. Kidd, J. Killeen, B. Law, and A.G. Watts, 225-33. London: Routledge.

Watts, A.G. 2001. Career education for young people: rationale and provision in the UK and other European countries. International Journal for Educational and Vocational Guidance 1, no. 3: 209-22.

Watts, A.G. 2006. Career development learning and employability. York: The Higher Education Academy.

Watts, A.G. 2008. Lessons learned from national reviews: Implications for the United States. Paper presented to an NCDA symposium on 'Strategic Leadership for Career Development in Public Policy: Identifying Challenges, Creating Solutions and Implementing Strategies', in Washington, DC, July 7-8.

Watts, A.G., and G. Dent. 2006. The 'P' word: Productivity in the delivery of career guidance services. British Journal of Guidance and Counselling 34, no. 2: 177-89.

Watts, A.G., and D.H. Fretwell. 2004. Public policies for career development: Policy strategies for designing career information and guidance systems in middleincome and transition economies. Washington, DC: The World Bank.

Watts, A.G., and R.G. Sultana. 2004. Career guidance policies in 37 countries: Contrasts and common themes. International Journal for Educational and Vocational Guidance 4, nos. 2-3: 105-22.

Watts, A.G., R.G. Sultana, and J. McCarthy. 2010. The involvement of the European Union in career guidance policy and practice: A brief history. International Journal for Educational and Vocational Guidance 10, no. 2: 89-107.

Whiston, S.C., T.L. Sexton, and D.L. Lasoff. 1998. Career intervention outcome: A replication and extension of Oliver and Spokane. Journal of Counseling Psychology, 45: 150-65.

Whitty, G., G. Rowe, and P. Aggleton. 1994. Subjects and themes in the secondary school curriculum. Research Papers in Education 9, no. 2: 159-81.

Wilson, B., and J. Wyn. 1983. Policies for youth: Approaches to school-work transition. In: Australian Association for Research in Education: Educational research for national development: policies, planning and politics. Canberra: AARE.

Zelloth, H. 2009. In demand: Career guidance in EU neighbouring countries. Turin: ETF. 